\title{
Blunt thoracic trauma with the formation of pseudoaneurysm with the junction of the right subclavian artery
}

\author{
(iD) Rodolfo Mendes Queiroz ${ }^{1}$ \\ Danilo Brotto Ferreira de Santana ${ }^{1}$ \\ Daniel Roque \\ Fred Bernardes Filho ${ }^{2}$ \\ Eduardo Miguel Febronio ${ }^{1}$ \\ Marcus Vinicius Nascimento Valentin ${ }^{1}$
}

1. DOCUMENTA - Hospital São Francisco - Department of Radiology and Imaging Diagnosis, Ribeirão Preto, SP, Brasil 2. Faculdade de Medicina de Ribeirão Preto da Universidade de São Paulo; Division of Dermatology, Department of Clinical Medicine, Ribeirão Preto, SP, Brasil

KEYWORDS: Thoracic injuries. Subclavian artery, non-penetrating wounds.

\section{INTRODUCTION}

A male, 27-year-old ambulating patient, assisted in the Emergency Medical Unit, complaining about pains in the anterior region of the cervicothoracic transition a few minutes ago. He reported that crashed into a car door when it was opened while riding a bicycle, causing an impact on right hemothorax, and falling to the ground. He denied prior comorbidities. At physical examination, it was noted a heart rate of 135 beats per minute, arterial pressure of 92/56 $\mathrm{mmHg}$ and respiratory frequency of 22 per minute; no hematoma, abrasions or puncturing and cutting wounds.

The Computed Tomography (CT) of the thorax was carried out, showing in the precontrast phase: mediastinal formation with soft tissue density and central region discreetly hyperdense with the junction of the right subclavian artery, discrete areas of ground-glass attenuations in both lungs, massive right hemothorax with passive pulmonary atelectasis partially ipsilateral (figures 1A and 1B). When administering the intravenous contrast media, the formation showed a filling-up, confirming a pseudoaneurysm of the right subclavian artery (figures $2 \mathrm{~A}$, 2B and 3A). No injuries were found.

During the assessments, the patients presented dyspnea and signs of hemodynamic instability. It was chosen the emergency surgical approach, evolving to a recent postoperative death.

Diagnosis: Blunt thoracic trauma with a mediastinal injury of great artery.

\section{DISCUSSION}

In traumas, the thorax is the third topography frequently affected (fatal at 20\%), and it is secondary es- 


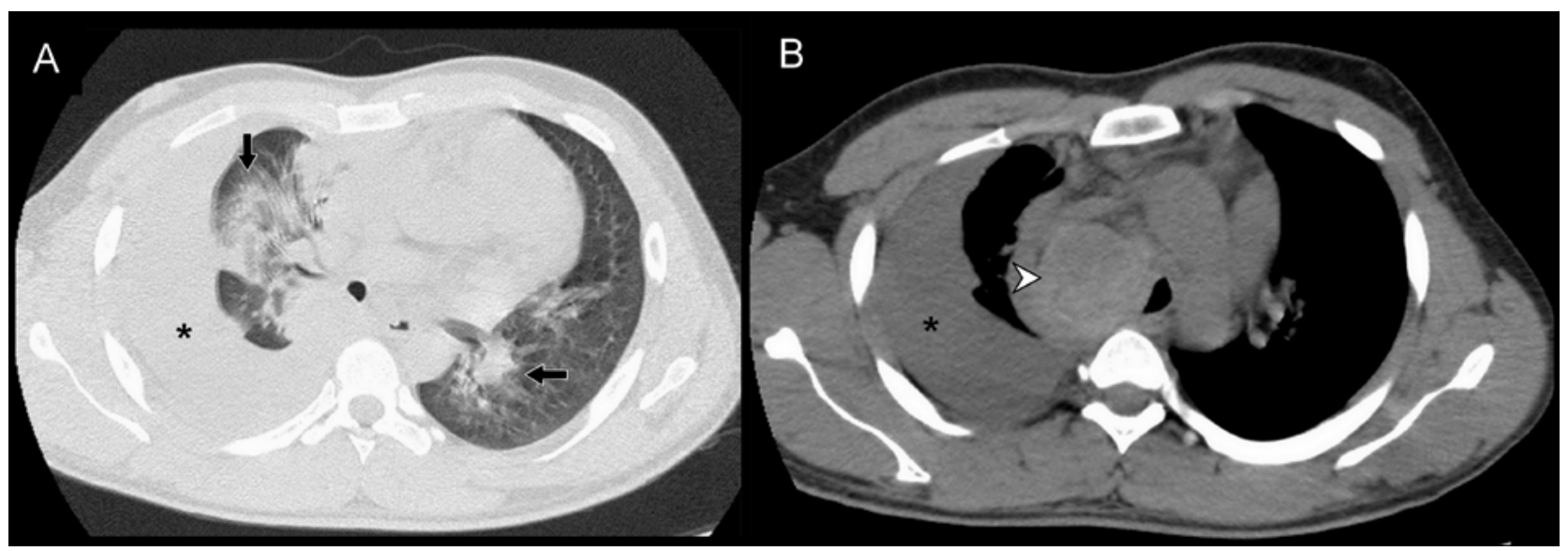

FIGURE 1. (A) High resolution axial tomographic section of the chest, pulmonary window showing discrete areas of groundglass attenuation in both lungs (black arrows), massive right pleural effusion ( ${ }^{\star}$ ) with ipsilateral partial passive pulmonary atelectasis. (B) Axial tomographic section without venous contrast showing evidence of mediastinal formation with soft tissue density and central region discretely hyperdense (white arrowhead), measuring approximately $7.7 \times 6.9 \times 4.1 \mathrm{~cm}$, determining contralateral mediastinal deviation and massive right pleural effusion $\left(^{*}\right)$.

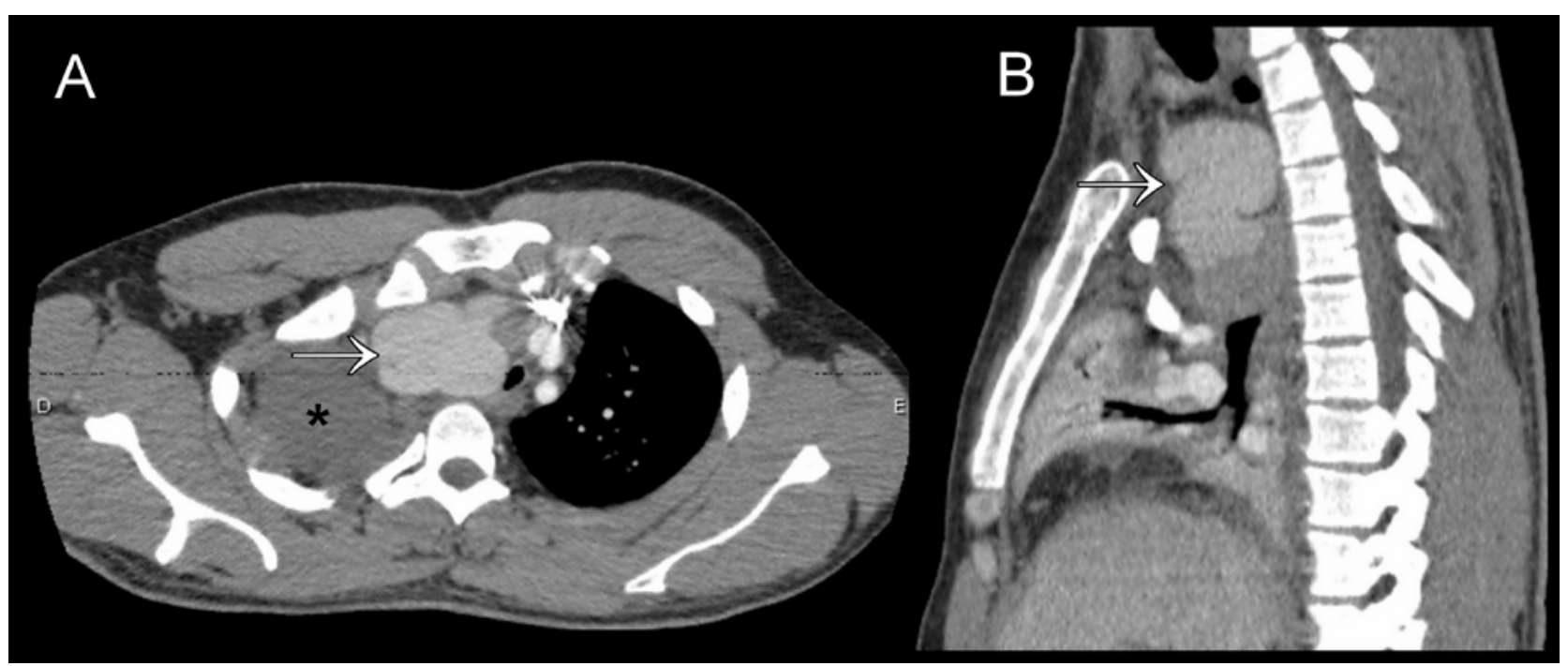

FIGURE 2. (C, D, E) Computed tomography imaging, axial (A) and sagittal (B) plans, demonstrating the filling of the formation by contrast after its intravenous administration (thin white arrow).

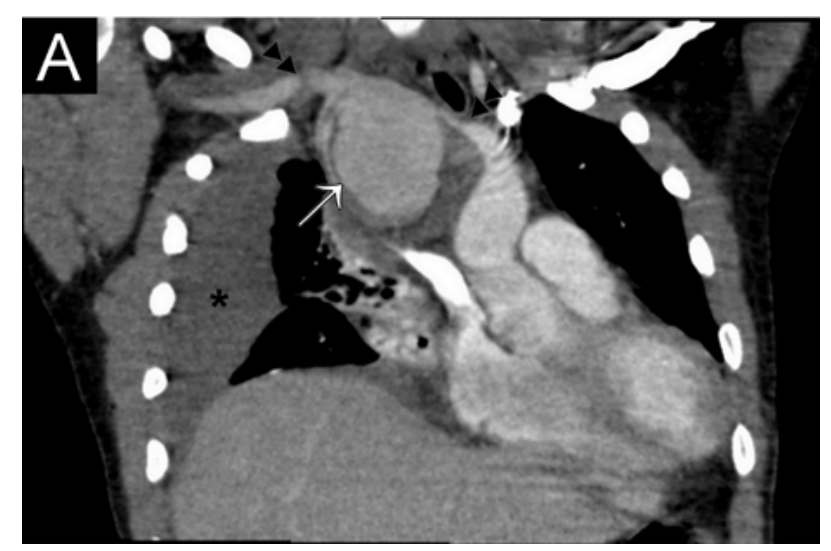

FIGURE 3. (A) Coronal tomographic reconstruction discretely oblique demonstrating the pseudoaneurysm filled by contrast after its intravenous administration (thin white arrow) and its intimate contact with the right subclavian artery (double black arrowhead). pecially to automobile accidents (66\%-85\%), in which young men ${ }^{1-4}$ are the victims

Classified in "penetrating" or "blunt", with a slight predominance of this second type. Some frequent changes: hemothorax, pneumothorax, pulmonary laceration-contusions injuries, herniations, tracheobronchial and diaphragmatic ruptures, esophageal and cardiac injuries, hematomas, pseudoaneurysms, ruptures and vascular dissections, fractures mainly of costal arches (if present in two or more sites of at least three ribs, it may be considered an "unstable thorax") $)^{\mathbf{1 , 5 , 6}}$.

In general, traumas involving aorta and great mediastinal vessels add approximately $5 \%$ of incidents; however, there is a high rate of mortality representing up to $15 \%$ of deaths in the automobile collisions. About $4 / 5$ of patients with aortic injuries die before intra-hospital care with a rate of up to 
$90 \%$ of death after 14 days of those who survive ${ }^{1-3}$.

The mechanisms of aortic injury and the junction of supra-aortic vessels involve pinchcock between the anterior thoracic wall and column; extension of neck and shoulder traction, respectively, with the action of sudden deceleration, traction, torsion, and hydrostatic forces ${ }^{\mathbf{1 7}}$.

The ascending aorta is rarely affected (5\%) due to its anchorage, where the arterial ligament ${ }^{1,2}$.

Pseudoaneurysms are very common in vascular wounds in this scope, characterized by hematic overflow by rupture of the layers in the arterial walls, organizing a hematoma in contact with the lumen, contained by adjacent and scar tissues ${ }^{7,8}$.

The radiography has a sensitivity of $90 \%$ and specificity of $10 \%$ for vascular injuries in this context, highlighting the signs: enlargement of mediastinum, blurring of aortic contours, paratracheal thickening ${ }^{1,4-6}$.

The angiography and CT are the best methods of assessment. CT has a predictive negative value of $100 \%$, with the advantage of not being so invasive, direct view of injuries and other non-vascular injuries; however, the use of intravenous contrast injection is very important in detecting vessels injuries ${ }^{1-5}$.

PALAVRAS-CHAVE: Traumatismos torácicos. Artéria subclávia. Ferimentos não penetrantes.

\section{REFERENCES}

1. Kaewlai R, Avery LL, Asrani AV, Novelline RA. Multidetector CT of blunt thoracic trauma. Radiographics. 2008;28(6):1555-70.

2. Melo ASA, Moreira LBM, Marchiori E. Lesões traumáticas do mediastino: aspectos na tomografia computadorizada. Radiol Bras. 2003;36(5):283-6.

3. O'Connor JV, Byrne C, Scalea TM, Griffith BP, Neschis DG. Vascular injuries after blunt chest trauma: diagnosis and management. Scand I Trauma Resusc Emerg Med. 2009;17:42.

4. Mioto Neto B, Aun R, Estenssoro AEV, Puech-Leão P. Tratamento das lesões de aorta nos traumatismos torácicos fechados. I Vasc Bras. 2005;4(3):217-26.
5. Palas J, Matos AP, Mascarenhas V, Herédia V, Ramalho M. Multidetector computer tomography: evaluation of blunt chest trauma in adults. Radiol Res Pract. 2014;2014:864369.

6. Escuissato DL, Warszawiak D. Trauma torácico. In: Santos Silva Cl, Müller NL, eds. Tórax - Série CBR. São Paulo: Elsevier; 2010. p.567-79.

7. Enamorado-Enamorado J, Egea-Guerrero J), Revuelto-Rey J, Gordillo-Escobar E, Herrera-Melero C. Left subclavian artery pseudoaneurysm after a traffic accident: a case report. Case Rep Crit Care. 2011;2011:451819.

8. Romanus AB, Mazer S, Carvalho Neto A, Liu CB, De Toni FS, Jacob GVV, et al. Pseudo-aneurismas: relato de dois casos e revisão da literatura. Radiol Bras. 2002;35(5):303-6. 